\title{
Facharzt für den erfolgreichen Kampf im Bürokratie-Dschungel?
}

\author{
Jürg Unger-Köppel \\ Dr. med., Mitglied des FMH-Zentralvorstandes, Departementsverantwortlicher Stationäre Versorgung und Tarife
}

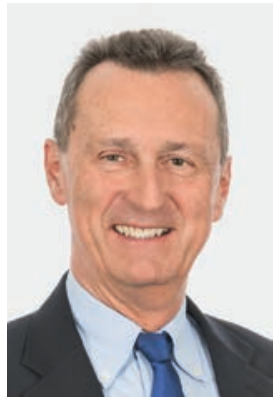

Der VSAO sagt es seit Jahren und unsere Umfrage mit gfsBern ${ }^{1}$ zeigt dasselbe Resultat seit Beginn der Erhebungen: Die administrative Last auf den Schultern der jungen Ärztinnen und Ärzte steigt stetig. Es könnte der Eindruck entstehen, die Facharztausbildung müsste vielmehr zu einem erfolgreichen Kampf durch den Bürokratie-Dschungel befähigen als zu guter Medizin am Patienten. Mit diesem Ziel aber nimmt niemand nach der Matura den anstrengenden Weg zum Staatsexamen in Humanmedizin auf sich. Die Mittelschulabgängerinnen und -abgänger träumen viel mehr mit gutem Grund von der Arbeit mit und für den Patienten. Das ist die grosse Attraktivität unseres Berufes die Arbeit für und mit Menschen!

Zugleich klagen wir über Nachwuchsmangel in den Spitälern. In den zentrumsnahen Spitälern ist die Situation meist etwas weniger akzentuiert als in den ländlicheren Regionen. Dort hört man oft den Satz: «Wir finden kaum noch Ärztinnen und Ärzte - und auch kaum Pflegekräfte».

Für die Spitäler mit Nachwuchsproblemen wird schnell die Spitalschliessung thematisiert, um dann gleich deren politische Unmöglichkeit zu beklagen. In dieser Situation sollte man besser über die Weiterentwicklung der Spitäler nachdenken, statt deren simple Schliessung herbeizureden. Allein die teure Infrastruktur verkommen zu lassen wie militärische Einrichtungen aus früheren Bedrohungslagen kann kein volkswirtschaftlich sinnvoller Weg sein. Gefragt sind neue Strukturen, die die Entwicklungen im Gesundheitswesen sinnvoll aufgreifen und pragmatischen Lösungen zuführen. Wie setzt man die Möglichkeiten der Telemedizin, vermehrte ambulante Behandlungspfade oder die geforderten Mindestfallzahlen um? Welche Strukturen ermöglichen die zeitgemässen Transportmöglichkeiten in den überall heraufbeschworenen fünf bis sieben Spitalregionen und wie setzt man diese Lösungen sinnvoll in ein funktionierendes ganzheitliches System um?

Gerade auch mit neu definierten Zielen brauchen die weiterentwickelten, peripheren Standorte innerhalb einer Spitalregion gut ausgebildete Ärztinnen und Ärzte, die solchen Aufgaben gewachsen sind. Die junge
Ärzteschaft neigt heute vermehrt dazu, in den Zentren zu bleiben, denn in zeitgemässen Beziehungen von gut ausgebildeten Paaren wollen meist beide einer anspruchsvollen Tätigkeit nachgehen. Was machen nichtärztliche Akademiker in Gegenden der Schweiz, die für sie keine Stellen bieten (können)? Wenn ein Paar keine Wochenendbeziehung führen will, fällt schnell der Entscheid zum Verbleib im Zentrum. Das heisst, Standorte weit weg von Zentren müssen besondere Anstrengungen unternehmen, um eine hohe Arbeitsplatzattraktivität zu erreichen.

Gute Ausbildner haben eine wichtige, geradezu magnetische Anziehungskraft für junge Ärztinnen und Ärzte. Zugleich sind immer mehr eben auch jene Spitäler erfolgreich bei der Rekrutierung, die sich so organisieren, dass die Assistenzärzteschaft mehr Patientenarbeit machen darf und weniger Administration erledigen muss. Zudem ist ein hoher Anteil an administrativem Aufwand in der Arbeitszeit von Ärztinnen und Ärzten unwirtschaftlich für die Spitäler. Schon eine kleine Verschiebung der Administration von Medizin und Pflege hin zu administrativen Fachpersonen hat ein wichtiges finanzielles Einsparpotential. Spitäler, die gemeinsam mit ihren Mitarbeitenden aktiv Wege suchen, um die Ärzteschaft zurück zu den Patienten zu bringen, bedienen zugleich noch viele weitere Ziele auf einen Schlag: Sie steigern damit die Zufriedenheit innerhalb der Ärzteschaft und erhöhen damit die Arbeitsplatzattraktivität. Sie sparen Kosten, denn die Ärztinnen und Ärzte werden gezielt für jene Tätigkeiten eingesetzt, für die sie unersetzlich sind. Sie ermöglichen es, mit weniger Ärztinnen und Ärzten die Aufgaben des Spitalstandortes wahrzunehmen. Und nicht zuletzt steigern sie damit auch die Patientenzufriedenheit, weil die Patienten ihre Ärztinnen und Ärzte so mehr zu Gesicht bekommen.

Deshalb würden Spitalverwaltungsräte sicher gut daran tun, in ihrer nächsten Sitzung den Auftrag zu geben, dass in ihrer Institution alles getan werden sollte, um im nächsten Jahr mit der VSAO-Spitalrose ausgezeichnet zu werden! (Siehe dazu auch den Artikel zur Verleihung der Spitalrose auf Seite 36.) 